\title{
The forensic autopsy as a teaching tool: Attitudes and perceptions of undergraduate medical students at the University of Pretoria, South Africa
}

\author{
L du Toit-Prinsloo, ${ }^{1} \mathrm{MB}$ ChB, DipForMed (SA) Path, FCForPath (SA), MMed (Path) (Forens); \\ G Pickworth, ${ }^{2}$ BSc, BSc Hons (Psych), MEd (Psych), DPhil (Psych); G Saayman, ${ }^{1}$ MB ChB, MMed (MedForens), FCForPath (SA)
}

${ }^{1}$ Department of Forensic Medicine, Faculty of Health Sciences, University of Pretoria, South Africa

${ }^{2}$ Department of Education Innovation, Faculty of Health Sciences, University of Pretoria, South Africa

Corresponding author: $L$ du Toit-Prinsloo (lorraine.dutoit@up.ac.za)

Background. Numerous articles have been published on the use of autopsies in training medical students in anatomy and different branches of pathology. Some authors have described the emotional response of students who attend such postmortem sessions. Forensic pathology is an important subdivision of pathology. In some countries undergraduate medical students are expected to attend postmortem examinations on persons who died from traumatic causes.

Objective. To determine the attitudes and perceptions of 5th-year medical students with regard to forensic postmortem examinations at the University of Pretoria, South Africa.

Methods. A questionnaire was voluntarily completed by medical students on the last day of the practical rotation.

Results. The overall rating of the practical rotation was $82 \%$. The strengths, weaknesses, opportunities and threats (SWOT) analysis indicated the following as strengths: record keeping, legislation review and traumatology description; as weaknesses: emotional trauma and nightmares; as opportunities: the attendance of autopsies; and as threats: physical dangers.

Conclusion. The current study was similar to international studies with regard to students' emotional response to attending autopsies. The autopsy remains a valuable teaching tool for undergraduate students. Emotional support is currently available for all students to assist them in overcoming their fear of attending forensic autopsy sessions.

Afr J Health Professions Educ 2016;8(1):77-80. DOI:10.7196/AJHPE.2016.v8i1.589

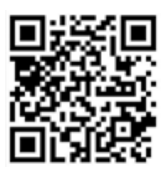

The use of the autopsy in teaching undergraduate medical students is a well-known worldwide practice. ${ }^{[1,2]}$ Autopsies are used for teaching anatomical and forensic pathology to under- and postgraduate students. Harris et al. ${ }^{[3]}$ reported that general practitioners regard autopsies as 'being of benefit to education and research. Their study excluded coroners' cases and was published as part of the first publication of the UK General Medical Council's Tomorrow's Doctors. ${ }^{[3]}$ Burton ${ }^{[4]}$ conducted a qualitative study on the use of the autopsy and the curriculum, indicating that the role of the former is multifactorial and can aid in teaching anatomy and clinicopathological correlations, can be a form of clinical audit and, in the forensic medicine setting, can aid in death certification. Burton included structured interviews with teachers of undergraduate medical students, including histopathologists, non-pathologists, general practitioners, surgeons and physicians. (No forensic pathologists were interviewed.) The participants in Burton's study indicated that although it is strongly advised that students be exposed to autopsies, they did not feel that it should be compulsory.

A number of articles have been written on the perceptions, views and attitudes of students after attending autopsies. In Germany, Tschernig et al. ${ }^{[5]}$ reiterated that the medical student's first encounter with corpses is usually during anatomy training. These authors indicate that even for the purpose of attending autopsies for anatomy training, students need to be prepared both psychologically and physically.

Benbow ${ }^{[6]}$ from the Division of Histopathology, Department of Pathological Services, University of Manchester, UK, distributed questionnaires to 2ndand 3rd-year undergraduate medical students, reviewing personal details and experiences as well as general questions about autopsies. The study indicated that medical students viewed the autopsies as useful, although some indicated that the only use is to determine the cause of death. The psychological effects indicated that some students could come to terms with death, while others found it 'difficult'. Physical symptoms included the worrisome smell, palpitations and tears.

Bataineh et al., ${ }^{[7]}$ from the Department of Anatomy at the Jordan University of Science and Technology, reviewed questionnaires from preclinical medical students, which indicated that $28.9 \%$ expressed a degree of fear before entering the autopsy room, $19.3 \%$ had palpitations and $50.3 \%$ were concerned about an infection risk.

It would appear that there is very little literature that reviews the perceptions of medical students who attend forensic pathology autopsies. At the University of Athens, Greece, Papadodima et al ${ }^{[8]}$ indicated that $50 \%$ of students who attended forensic autopsies were fearful and anxious, with some experiencing physical symptoms such as nausea. Sergentanis et al. ${ }^{[9]}$ did a follow-up study with the objective of identifying risk factors for the psychological reactions experienced during the forensic medical practical rotation. The authors identified the following risk factors: female gender and 'stereotypic beliefs about forensic pathologists, a more emotional frame of mind with regard to forensic dissection, more passive coping strategies, and greater fear of death'.

He et al. ${ }^{[10]}$ from the Department of Pathology, Shanghai Hospital, Second Military Medical University, China, reviewed the perceptions of medical students who attended autopsies on individuals who had died from unnatural causes. The students were enrolled voluntarily and divided into groups to view the autopsies from behind a glass partition on television screens linked to a camera, or stood next to the autopsy table. They indicated the advantages of attending the autopsies, e.g. with regard to anatomy teaching: 'the autopsy is a valuable tool to clinical practice and analysis of 
wound condition and wound rescue in future work'; a method to 'correlate information from different sources'; and 'the autopsy is the epitome of problem-based learning. ${ }^{\text {[10] }}$ Disadvantages included that it was physically 'unpleasant and frightening' and also 'an autopsy in human terms is a horrendous thing to do ... the mortuary room is a dangerous place. ${ }^{\text {[10] }}$ The authors indicated that the primary objective of the autopsy is to teach pathology; yet, most students indicated its helpfulness in teaching anatomy. The concluding remarks include that the students had a positive attitude towards autopsy (despite discomfort) and its multifactorial role.

In South Africa (SA), a study by De Villiers and Ruhaya ${ }^{[11]}$ from the Department of Paediatrics at the University of Limpopo (Medunsa Campus) (currently Sefako Makgatho Health Sciences University, Pretoria) reviewed questionnaires completed by final-year medical students after autopsies conducted in anatomical pathology. Twenty-two percent of students indicated that they felt that the corpses were handled disrespectfully, 58\% that the first autopsy attendance was rewarding, and most (it is not exactly quantified) felt uncomfortable, with some experiencing nightmares.

In forensic pathology training in SA, many of the medical schools require that undergraduate medical students attend forensic postmortem examinations. In a study by McNamee et al., ${ }^{[12]}$ from the Department of Forensic Medicine, Nelson R Mandela School of Medicine, University of KwaZulu-Natal, Durban, 10 students took part in semistructured interviews after completion of the forensic medicine practical rotation. All students experienced a degree of discomfort, $70 \%$ indicated that they had a better understanding of the mechanism of death and could better differentiate between natural and unnatural causes of death, and $80 \%$ indicated that the description of trauma aided a great deal.

The current study was undertaken in the Department of Forensic Medicine, University of Pretoria, where 5th-year medical students voluntarily completed a questionnaire after completing a 2-week practical rotation in forensic pathology. The objective was to review perceptions and attitudes of students towards the practical rotation.

\section{Methods}

At the University of Pretoria, 5th-year medical students attend a 2-week practical rotation in the Department of Forensic Medicine (8 consecutive groups). The facility at the Forensic Pathology Service, Medico-Legal Laboratory, Pretoria consists of a large dissection hall with three dissection stations, where the bodies are placed next to each other and opened; organs are eviscerated in the hall and dissected at the dissection stations. Adjacent to the large dissection hall is an autopsy amphitheatre, with a door opening into the large hall. In the autopsy theatre the students have a direct view of the dissection station. The bodies are brought into the theatre in order that an external examination can be performed, but the physical opening of the bodies and evisceration of the organs are conducted in the large dissection hall (behind the door). The students in the theatre view the organ dissection. Each student rotation consisted of $\sim 30$ students who were divided into two groups - a large group of $\sim 20$, who were seated in the theatre and observed the postmortem examinations, and a smaller group of $\sim 10$, who stood in the dissecting room. During the 2 weeks, the students were rotated between the large and small groups. Each student therefore attended $\sim 10$ postmortem examination sessions (each session lasted $\sim 90$ minutes). Of special note is that the daily cases are viewed prior to the arrival of the students and severely mutilated or decomposed bodies are not shown to the students. After the practical postmortem sessions, the students attended tutorial sessions in a lecture room at the mortuary. These lasted up to 2 hours each and were conducted as PowerPoint presentations, providing information on topical issues, such as death notification and legislation, which are not taught in formal lectures. In 2011, the year of the current study, no specific emotional support or preparation was provided to students before commencement of the rotation.

At the end of the 2-week rotation, the students were asked to voluntarily complete a questionnaire. The questionnaire was divided into four parts:

- Part A (quantitative): 10 general questions regarding the information provided to students, expectations and organisation. Students indicated their response on a scale of 1 (strongly disagree) - 5 (strongly agree).

- Part B (quantitative): the students provided an overall rating of the practical rotation on a scale of $1-10$.

- Part C (qualitative): the so-called strengths, weaknesses, opportunities and threats (SWOT) analysis was used and the students could write their responses under each component.

- Part D (qualitative): space was provided for the students to write recommendations.

\section{Results}

In 2011, 220 students were enrolled for the 5th-year of the MB ChB degree. A total of 212 (96\%) students completed the voluntary questionnaire at the end of the forensic medicine practical rotation.

\section{Part A. General information: Quantitative}

Table 1 summarises the average obtained for each of the questions.

\section{Table 1. General information}

\begin{tabular}{ll}
\hline Question & Average, \% \\
\hline $\begin{array}{l}\text { We were well informed where we had to be on the first day of } \\
\text { the rotation }\end{array}$ & 93 \\
We received sufficient information on what would be expected & 86 \\
of us in the rotation & \\
$\begin{array}{l}\text { The outcomes and objectives of the rotation, as well as the way } \\
\text { in which we would be evaluated, were clearly communicated }\end{array}$ & 83 \\
to us & \\
We had sufficient exposure to forensic postmortem & 92 \\
examinations (variety of cases) and the medicolegal & \\
investigation of death & 92 \\
$\begin{array}{l}\text { Our time was used very effectively } \\
\text { The tutorial sessions were well presented and informative } \\
\text { The evaluation assessed what we had learned in the rotation }\end{array}$ & 91 \\
The consultants and registrars made positive inputs towards & 90 \\
our training & \\
The personal protective equipment in the mortuary was up to & 85 \\
standard & \\
The rotation was well organised & 92
\end{tabular}

\section{Part B. Overall rating of the rotation: Quantitative}

All eight groups indicated a score of $>8 / 10$ as a general impression of the rotation (with an average of $82 \%$ ). 


\section{Part C. SWOT analyses: Qualitative}

\section{Strengths}

Several of the students indicated the following as strengths:

- the emphasis on applicable legislation pertaining to medical practitioners

- the practical exposure and opportunity to attend autopsies

- the importance of proper record-keeping

- recognising the different aspects of death

- how to deal with death ('how to cope with dramatic deaths and injuries')

- differentiating between deaths due to natural and unnatural causes

- the nature of injuries and the terminology of trauma, which were explained

- how to determine the cause of death

- revision of anatomy.

\section{Weaknesses}

Students indicated that:

- they experienced the rotation as emotionally traumatising $(n=64)$

- the rotation showed 'too much death and dying' and they were 'being exposed to death in such a brutal manner'

- the smell was worrisome $(n=4)$, and he/she experienced nightmares $(n=1)$

- he/she could not continue the rotation after 3 days of exposure (owing to nightmares) $(n=1)$

- there had been no debriefing $(n=2)$

- the rotation was too short $(n=4)$.

\section{Opportunities}

\section{Students indicated that:}

- a wide variety of cases were seen $(n=35)$

- the attendance of autopsies was an opportunity to learn pathology and anatomy, as normal and abnormal findings were seen $(n=15)$

- the attendance taught them the procedure being followed and what to expect during an autopsy $(n=8)$

- information regarding medical negligence was provided $(n=7)$

- the rotation was a 'good learning opportunity', but they did not elaborate on the statement $(n=5)$

- they learned a lot about the common causes of death in the medicolegal environment in SA $(n=3)$

- one can 'overcome fear of death' $(n=1)$

- he/she would consider forensic pathology as a specialty $(n=1)$.

\section{Threats}

Students indicated that:

- personal protective equipment was insufficient $(n=6)$

- they were worried about the risk of infections, specifically tuberculosis $(n=2)$

- the bodies or organs were handled disrespectfully $(n=2)$

- awareness of medical negligence was highlighted $(n=4)$.

\section{Part D. Recommendations}

Students recommended that:

- attendance should not be compulsory $(n=2)$

- there should be fewer postmortem sessions $(n=2)$

- the practical rotation should be longer $(n=5)$

- a debriefing session/better emotional preparation is needed prior to commencement of the practical session $(n=5)$.

\section{Discussion}

The training of undergraduate medical students differs worldwide. In SA, the Health Professions Council of South Africa (HPCSA) is the governing body for healthcare practitioners and prescribes the clear minimum standards of training for medical students. In the core competency lists provided by the HPCSA, the exact curriculum and expectations for forensic medicine/pathology are not clearly stipulated. ${ }^{[13]}$

The autopsy is a valuable tool when teaching several important branches of medicine to undergraduate students, such as anatomy and pathology. ${ }^{[1,2]}$ Undergraduate students are exposed to different forms of learning with regard to the deceased. At most institutions, anatomy teaching exposes students to embalmed bodies, where they often perform the dissections. Attending postmortem examinations in pathology - anatomical as well as forensic - entails viewing a non-embalmed body (in the majority of cases). At the University of Pretoria, medical students attend most of the anatomy dissections in the 2nd year of study, anatomical pathology in the 3 rd year and the forensic pathology practical rotation in the 5th year (the undergraduate degree comprises 6 years of study at our institution). The difference in the type of body seen and the expected teaching and learning outcomes makes it difficult to compare studies on the role of the autopsy as a teaching tool.

Tschering et al. ${ }^{[5]}$ pointed out that the first encounter with human bodies is usually in the anatomy dissection hall and they refer to the provocative question posed by Lippert in 1985: 'How humane is human anatomy and to what extent will the behaviour of a medical student during dissection influence his/her future attitude to patients?'

The current study was smilar to other international studies with regard to students' emotional responses to attending forensic autopsies. ${ }^{[8-10]}$ It would appear that there is a degree of ambiguity in their response to the practical rotation, as the sessions were generally regarded as a positive learning experience, with the overall impression receiving a score of $>8 / 10$; yet, $30 \%$ of the students indicated an emotional aspect (seeing too much of death). An explanation for this discrepancy could be that most of the questions in part A relate to the administration of the rotation (time management, tutorial sessions and assessments), with one question phrased as 'We had sufficient exposure to forensic postmortem examinations (variety of cases) and the medicolegal investigation of death. The students scored the latter question $92 \%$, and it could be that even those who found the rotation emotionally distressing agreed that they had 'sufficient exposure'. A second reason could be that the SWOT analysis might not have been the best tool with which to evaluate the perceptions of students. The study also reiterated the findings of McNamee et al. ${ }^{[12]}$ regarding the emotional aspect surrounding the attendance of forensic autopsies, indicating that the autopsy aided in the description of trauma and differentiated between natural and unnatural causes of death.

Statistics SA ${ }^{[14]}$ specified that in 2010, 543856 people died in SA, a country with an estimated population of $\sim 50$ million. Of these deaths, 48377 were due to unnatural causes. This indicates and emphasises the importance of training undergraduate medical students in the legislation pertaining to registering deaths correctly and how to recognise a death as being due to an unnatural cause. Furthermore, there are only 50 forensic pathologists in SA. This implies that a large number of medicolegal postmortem examinations are being conducted by general practitioners - a reality that further emphasises the importance of training undergraduate medical students in the field.

At the University of Pretoria, student feedback confirmed that some students experience emotional distress relating to forensic autopsy sessions. 
This highlights the need to address both the educational goals and emotional impact for students. Emotional support has been introduced, with clinical psychologists being available to students who find it difficult to cope with the forensic autopsy sessions. Currently, a clinical psychologist addresses the entire group at the mortuary after the first postmortem session (due to other clinical engagements this was the only feasible session) and on the last Thursday of the 2-week rotation. During the first session, the clinical psychologist provides a contact number to initiate further emotional support, should the individual need arise. The feedback forms pointed out that all applicable SA legislation is made available to students, and the emphasis of the practical session is on teaching what a generalist medical practitioner should know.

\section{Conclusion}

The autopsy as part of the undergraduate training of medical students remains an invaluable tool. In a country with a high number of violent and unnatural deaths, appropriate teaching regarding legislation and management of victims (especially appropriate referral for medicolegal investigation in cases of death) cannot be neglected. Provision needs to be made to support medical students who experience the rotation as emotional. The current study only reflects the opinions of medical trainees and does not represent objective measuring of the evidence of the learning of these students.
Acknowledgements. The authors would like to thank Mmes V Tredoux and H Malherbe from the Department of Education Innovation at the Faculty of Health Sciences, University of Pretoria for capturing the data onto the system. Special thanks also to Ms B English from the Faculty of Health Sciences for the language editing of the article.

\section{References}

1. DeRoy AK. The autopsy as a teaching-learning tool for medical undergraduates. J Med Educ 1976;51:1016-1018. [http://dx.doi.org/10.1097/00001888-197612000-00011]

2. Hill RB, Anderson RE. The uses and value of autopsy in medical education as seen by pathology educators. Acad Med 1991;66:97-100. [http://dx.doi.org/10.1097/00001888-199102000-00011]

3. Hed 1991;66:97-100. [http://dx.doi.org//0.10970001888-199102000-00011] 1 Physicians Lond 1993:27:116-118.

3. Harris A, Ismail I, Dilly S, Maxwell JD. Physicians attitudes to the autopsy. J R Coll Physicians Lond 1993;27:116-118.
4. Burton JL. The autopsy in modern undergraduate medical education: A qualitative study of uses and curriculum 4. Burton JL. The autopsy in modern undergraduate medical education: A qualitative study of uses and
considerations. Med Educ 2003;37:1071-1081. [http://dx.doi.org/10.1046/j.1365-2923.2003.01710.x]

5. Tschernig T, Schilaud M, Pabst R. Emotional reactions of medical students to dissecting human bodies: A conceptual approach and its evaluation. Anat Rec 2000;261(1):11-13.

6. Benbow EW. Medical students' views on necropsies. J Clin Pathol 1990;43:969-976. [http://dx.doi.org/10.1136/jcp.43.12.969] 7. Bataineh ZM, Hijazi TA, Hijleh MF. Attitudes and reactions of Jordanian medical students to the dissecting room. Surg Radiol Anat 2006;28(4):416-421. [http://dx.doi.org/10.1007/s00276-006-0101-4]

8. Papadodima SA, Sergentanis TN, Illiaki RG, Sotiropoulos KC, Spiliopoulou CA. Students who wish to specialize in forensic medicine vs. their fellow students: Motivations, attitudes and reactions during autopsy practice. Adv Health Sci Educ Theory Pract 2008;13:535-546. [http://dx.doi.org/10.1007/s10459-007-9065-3]

9. Sergentanis TN, Papadodima SA, Evaggelakos CI, Mytilinaios DG, Goutas ND, Spiliopoulou CA. Students physical and psychological reactions to forensic dissection: Are there risk factors? Anat Sci Educ 2010:3(6):287294. [http://dx.doi.org/10.1002/ase.182]

10. He M, Wang $\mathrm{J}$. Zhu Z, et al. A survey study of military medical students to autopsy in modern medical education. Scientific Research and Essays 2011;6(32):6666-6670. [http://dx.doi.org/10.5897/SRE11.1197]

11. De Villiers FPR, Ruhaya M. Students' opinions on autopsy and death. SA Fam Pract 2005:47(1):47-50. [http:// dx.doi.org/10.1080/20786204.2005.10873172]

12. McNamee LS, O'Brien FY, Botha JH. Student perceptions of medico-legal autopsy demonstrations in a studentcentred curriculum. Med Educ 2009;43:66-73. [http://dx.doi.org/10.1111/j.1365-2923.2008.03248.x]

13. Health Professions Council of South Africa. www.hpcsa.co.za (accessed 14 December 2015).

14. Statistics South Africa. Mortality and causes of death in South Africa, 2010: Findings from death notification. http://www.statssa.gov.za/publications/P03093/P030932010.pdf (accessed 16 March 2014). 